\title{
Synergistic Effect of Nanosilica Aerogel with Phosphorus Flame Retardants on Improving Flame Retardancy and Leaching Resistance of Wood
}

\author{
Xiaodan Zhu, Yiqiang Wu, Cuihua Tian, Yan Qing, and Chunhua Yao \\ Material Science and Engineering College, Central South University of Forestry and Technology, Changsha, Hunan 410004, China \\ Correspondence should be addressed to Yiqiang Wu; wuyq0506@126.com
}

Received 25 April 2014; Accepted 18 June 2014; Published 6 July 2014

Academic Editor: Sanqing Huang

Copyright (c) 2014 Xiaodan Zhu et al. This is an open access article distributed under the Creative Commons Attribution License, which permits unrestricted use, distribution, and reproduction in any medium, provided the original work is properly cited.

Nanosilica ( $\mathrm{Nano}-\mathrm{SiO}_{2}$ ) sol fabricated by a sol-gel process was introduced into wood modification with phosphorus flame retardants to improve the flame retardancy and leaching resistance of wood. The obtained materials were characterized by scanning electron microscopy and energy dispersive spectrometer (SEM-EDS), thermogravimetric analysis (TGA), cone calorimetric (CONE), and infrared spectroscopy (FT-IR). The residual rate of flame retardants before and after leaching was determinated by a leaching resistance. The results showed that the phosphorus flame retardants and $\mathrm{SiO}_{2}$ sol could reside in the poplar wood and are widely distributed in the vessels, pits, wood timber, and the spaces between wood cells of poplar substrate. TGA and CONE results indicated that the introduction of nano- $\mathrm{SiO}_{2}$ aerogel with phosphorus flame retardants had a significantly synergistic effect on improving the flame retardancy and inhibiting the release of smoke and toxic gases. In addition, the leaching resistance test, combined with infrared analysis and EDS analysis, confirmed that the phosphorus flame retardants were able to be fixed by $\mathrm{SiO}_{2}$ aerogel in the wood.

\section{Introduction}

Wood is the only truly sustainable resource. Its unique advantages such as good visual characteristics, tactile properties, nontoxicity have made it one of the most important materials in the furniture, building, and construction industries. However, wood is combustible due to its organic constitution, which may not only lead to the spread of fire but also produce a large number of smoke and toxic gases like $\mathrm{CO}$, the leading cause of casualties. Therefore, in order to gain safe and environmentally friendly wood materials, the wood products with fire retardation and smoke suppression are needed urgently.

Inorganic chemicals are attracting more and more attention among common fire retardants due to their high flame retardant efficiency, low cost, and environmental friendliness [1-4]. Specifically, phosphorus flame retardants like ammonium polyphosphate (APP) and ammonium monohydric phosphate (DAP) are effective fire retardants and have been widely used for fire retardation treatment of wood and other cellulosic combustible materials [5-8]. However, the inorganic salts of the flame retardants are water-soluble, resulting in a gradual loss during using terms, which directly affect the durability of fire-retardant properties, thus limiting its use in contact with water or humidity. What is more, with the use of phosphorus flame retardants, more gases like CO are produced which result in the suffocation of people [9]. Therefore, nontoxic, leach resistance smoke suppression will be a trend in the development of flame retardants for wood.

The inorganic nano- $\mathrm{SiO}_{2}$ aerogel plays a certain role in the adsorption and blocking action, which shows a porous structure when it is resided in interior materials. Meanwhile, the $\mathrm{Si}$ element existed in $\mathrm{SiO}_{2}$ aerogel, combined with $\mathrm{P}$ or $\mathrm{N}$ presented in phosphorus flame retardants, exert a certain synergistic flame retardant and smoke suppression effect $[10,11]$. What is more, nano- $\mathrm{SiO}_{2}$ aerogel has large specific surface area and strong adsorbability, which may help to prevent the phosphate flame retardant from running off [12]. Hence, in this work, nano- $\mathrm{SiO}_{2}$ aerogel, obtained by sol-gel method, was used to combine with three different phosphate 


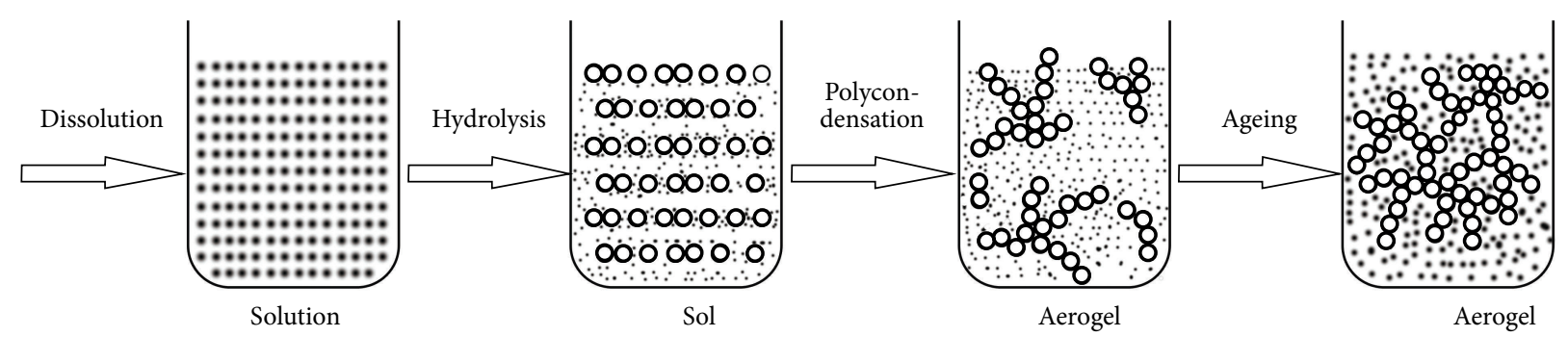

FIGURE 1: Basic schematic diagram of sol-gel process.

flame retardants to treat wood in order to improve the flame retardancy and smoke suppression and leaching resistance of wood.

\section{Materials and Methods}

2.1. Materials. Poplar wood (Populus deltoides cv. I-69/55) was obtained from Yiyang Forest, Hunan. Wood specimens were cut from untreated poplar sapwood into wood blocks with dimensions of $100 \mathrm{~mm} \times 10 \mathrm{~mm} \times 100 \mathrm{~mm}$ and $20 \mathrm{~mm} \times$ $20 \mathrm{~mm} \times 20 \mathrm{~mm}(\mathrm{~T} \times \mathrm{R} \times \mathrm{L})$, whose moisture content was 8$12 \%$. Tetraethyl orthosilicate (TEOS, $\left.\mathrm{C}\left(\mathrm{SiO}_{2}\right) \geqslant 98 \%\right)$, ethanol (ET), and hydrochloric acid ( $\mathrm{HCl}, 36-38 \%)$ which were all analytically pure were purchased from XiLong Chemical Co., Ltd., while distilled water $\left(\mathrm{H}_{2} \mathrm{O}\right)$ was prepared in the laboratory. Phosphorus flame retardants including ammonium polyphosphate (APP), ammonium monohydric phosphate (DAP), and ammonium phosphate (AP) were supported by Shanghai Luzhong Chemical Product Co., Ltd. APP, DAP, and $\mathrm{AP}$ were dissolved in water, respectively, to prepare three kinds of solutions of $10 \%$ mass fraction.

2.2. Preparation of Nano-SiO ${ }_{2}$ Aerogel. The $\mathrm{SiO}_{2}$ aerogel with nanoporous network structure was made by sol-gel method. The preparation was shown in Figure 1 . The TEOS/ET/ $\mathrm{H}_{2} \mathrm{O}$ with a molar ratio of $1: 5: 8$ were poured into the reaction system. To promote the hydrolysis process, $\mathrm{HCl}$ was added until the $\mathrm{pH}$ value was 3 . The mixture solution was stirred at $50^{\circ} \mathrm{C}$ for 60 min until the solution was clear.

2.3. Preparation of Nanosilica Aerogel with Phosphorus Flame Retardants Treated Wood. The poplar wood specimens were treated with flame retardants by impregnation method. The prepared solutions of APP, DAP, and AP were impregnated into poplar wood specimens at room temperature under a high pressure $(0.5 \mathrm{MPa})$ for $40 \mathrm{~min}$, respectively, while $\mathrm{H}_{2} \mathrm{O}$ was impregnated into wood at the same condition as control group. The impregnated specimens were then placed in an oven controlled to be $60^{\circ} \mathrm{C}$ for $24 \mathrm{~h}$. In addition, half of the impregnated samples again with the silica sol solution were treated under the same process condition as mentioned above. After that, they were placed in an oven controlled at $60^{\circ} \mathrm{C}$ for $24 \mathrm{~h}$ and at $105^{\circ} \mathrm{C}$ for another $24 \mathrm{~h}$ to age the gels until $\mathrm{SiO}_{2}$ aerogel formed in the cell of wood. The specific formula
TABLE 1: Formula of impregnation experiment for untreated and treated wood.

\begin{tabular}{lccccc}
\hline Samples & $\mathrm{H}_{2} \mathrm{O}$ & $\mathrm{APP}$ & $\mathrm{DAP}$ & $\mathrm{AP}$ & $\mathrm{SiO}_{2}$ sol \\
\hline S0 & $\mathrm{Y}$ & $\mathrm{N}$ & $\mathrm{N}$ & $\mathrm{N}$ & $\mathrm{N}$ \\
S1 & $\mathrm{N}$ & $\mathrm{Y}$ & $\mathrm{N}$ & $\mathrm{N}$ & $\mathrm{N}$ \\
S2 & $\mathrm{N}$ & $\mathrm{N}$ & $\mathrm{Y}$ & $\mathrm{N}$ & $\mathrm{N}$ \\
S3 & $\mathrm{N}$ & $\mathrm{N}$ & $\mathrm{N}$ & $\mathrm{Y}$ & $\mathrm{N}$ \\
S4 & $\mathrm{N}$ & $\mathrm{Y}$ & $\mathrm{N}$ & $\mathrm{N}$ & $\mathrm{Y}$ \\
S5 & $\mathrm{N}$ & $\mathrm{N}$ & $\mathrm{Y}$ & $\mathrm{N}$ & $\mathrm{Y}$ \\
S6 & $\mathrm{N}$ & $\mathrm{N}$ & $\mathrm{N}$ & $\mathrm{Y}$ & $\mathrm{Y}$ \\
\hline
\end{tabular}

Note. $\mathrm{Y}$ is short for Yes. $\mathrm{N}$ is short for No.

of impregnation experiment of every group could be seen in Table 1.

\subsection{Evaluation and Characterization}

2.4.1. Weight Percent Gain (WPG). The WPG of the samples $(20 \mathrm{~mm} \times 20 \mathrm{~mm} \times 20 \mathrm{~mm}(\mathrm{~T} \times \mathrm{R} \times \mathrm{L}))$ was determined on an oven-dried weight basis as shown in (1), by measuring the oven-dried weights of untreated specimens $\left(M_{0}\right)$ and the composite specimens $\left(M_{1}\right)$ :

$$
\mathrm{WPG}=\frac{M_{1}-M_{0}}{M_{0}} \times 100 \% .
$$

2.4.2. Leaching Resistance. The prepared wood blocks including untreated and treated ones $(20 \mathrm{~mm} \times 20 \mathrm{~mm} \times 20 \mathrm{~mm}$ $(\mathrm{T} \times \mathrm{R} \times \mathrm{L})$ ) were subject to a leaching test in a certain flow rate of water for $24 \mathrm{~h}$. After the test, the specimens were removed out to dry in an air atmosphere for $24 \mathrm{~h}$. After which, they should be placed in an oven controlled to be $60^{\circ} \mathrm{C}$ for another $24 \mathrm{~h}$ and then set to be $103^{\circ} \mathrm{C}$ until the weight was almost the same.

2.4.3. Microstructure Observation. Small samples with dimensions of $10 \mathrm{~mm} \times 20 \mathrm{~mm} \times 3 \mathrm{~mm}(\mathrm{~T} \times \mathrm{R} \times \mathrm{L})$ were cut from the untreated and treated poplar wood, which were located $3 \mathrm{~mm}$ from each radial, tangential, and transverse surface of the wood. Before observing the samples with a scanning electron microscope (SEM, FEI Quanta 450) at an accelerating voltage of $20 \mathrm{kV}$, each sample surface should be sputter-coated with a thin layer of gold. The element composition was determined by regional analysis using an 
TABLE 2: Mass variety of different stage for untreated and treated poplar wood.

\begin{tabular}{|c|c|c|c|c|c|c|c|c|}
\hline Samples & $W_{0}^{\mathrm{a}}(\mathrm{g})$ & $W_{1}^{\mathrm{a}}(\mathrm{g})$ & $W_{2}^{\mathrm{a}}(\mathrm{g})$ & $\mathrm{WPG}^{\mathrm{b}}(\%)$ & $\mathrm{RL}^{\mathrm{c}}(\%)$ & $\mathrm{ERL}^{\mathrm{d}}(\%)$ & $\operatorname{RSFR}^{\mathrm{e}}(\%)$ & $\operatorname{LRV}^{\mathrm{f}}(\%)$ \\
\hline S0 & 2.8811 & 2.8811 & 2.8673 & 0 & & 0.48 & & \\
\hline S1 & 3.3466 & 3.795 & 3.4283 & 13.40 & 9.66 & & 4.22 & 31.46 \\
\hline S2 & 3.2395 & 3.6746 & 3.2906 & 13.43 & 10.45 & & 2.98 & 22.19 \\
\hline S3 & 3.3678 & 3.8283 & 3.4149 & 13.67 & 10.80 & & 2.88 & 21.03 \\
\hline S4 & 3.2961 & 3.9796 & 3.6510 & 20.73 & 8.26 & & 12.48 & 60.18 \\
\hline S5 & 3.4955 & 4.1337 & 3.8157 & 18.26 & 7.69 & & 10.56 & 57.87 \\
\hline S6 & 3.1912 & 3.7708 & 3.4628 & 18.16 & 8.17 & & 9.99 & 55.03 \\
\hline
\end{tabular}

${ }^{\mathrm{a}} W_{0}$ : weight of untreated wood. $W_{1}$ : weight of treated wood after impregnation experiment. $W_{2}$ : weight of treated wood after leaching test. ${ }^{\mathrm{b}}$ WPG (weight percent gain) $=\left(W-W_{0}\right) / W_{0} \cdot{ }^{\mathrm{c}} \mathrm{RL}$ (average turnover rate) $=\left(W_{1}-W_{2}\right) / W_{1} \cdot{ }^{\mathrm{d}}$ ERL was the average turnover rate of untreated wood. ${ }^{\mathrm{e}} \mathrm{RSFR}$ (rest loading efficiency) $=$ WPG - RL + ERL. ${ }^{\mathrm{f}} \mathrm{LRV}$ (leaching resistance value) $=$ RSFR/WPG.

energy dispersive spectrometer (EDS) combined with the SEM.

2.4.4. Thermogravimetric Analysis (TGA). TG data of the untreated and treated wood powder were obtained using a Pyris-6 thermal analyzer. Each sample powder of about $8 \mathrm{mg}$ was placed in a platinum crucible and heated at the rate of $10^{\circ} \mathrm{C} / \mathrm{min}$ from ambient temperature to $700^{\circ} \mathrm{C}$. The flow of dynamic carrier nitrogen gas was set at a rate of $40 \mathrm{~mL} / \mathrm{min}$.

2.4.5. Cone Calorimetric (CONE) Test. The CONE tests of the untreated and treated wood were performed on Stanton Redcroft Inc. (Fire Testing Technology) following ISO5660-1. For each test, the specimen $(100 \mathrm{~mm} \times 10 \mathrm{~mm} \times 100 \mathrm{~mm}(\mathrm{~T} \times$ $\mathrm{R} \times \mathrm{L}$ )) covered with aluminum foil except the upper surface was placed into a specific steel frame, and the steel frame was mounted horizontally on the loader and exposed to the heat radiation of $50 \mathrm{kw} \cdot \mathrm{m}^{-2}$. This heat radiation corresponded to a temperature of $780^{\circ} \mathrm{C}$ on the upper surface of test sample.

\subsubsection{Fourier Transform Infrared Spectrometer (FTIR) Analy-} sis. For testing the change of chemical bonds and the combination mode between functional components and poplar wood, the method of tabletting with $\mathrm{KBr}$ was used with FTIR (IRAffinity-1). The powder of untreated and treated specimens was oven-dried, and the $\mathrm{KBr}$ was dried at $200^{\circ} \mathrm{C}$ in a muffle oven for $24 \mathrm{~h}$. Subsequently, the testing sample was obtained by mixing about 1-2 mg oven dried samples with 100-200 mg KBr. The FTIR curves of samples were obtained at the test scanning range of $4000-400 \mathrm{~cm}^{-1}$.

\section{Results and Discussion}

3.1. Weight Percent Gain (WPG) and Leaching Resistance. The impregnation experiment and leaching resistance test are evaluated by weight percent gain (WPG) and leaching resistance value (LRV), respectively. Every group has been prepared with ten samples to calculate the average weight. As we know, the mass of fire-retardant treated wood decreases after the extraction with water, which means the fire retardant is lost during the process of extraction. The LRV is the percentage of residue loading efficiency after extraction (RSFR) to the WPG. The lager the LRV is, the better the performance of leach resistance will be [13]. The results of mass variety of different stages for untreated and treated wood are shown in Table 2.

It can be seen from Table 2 that the WPG of phosphate flame retardant treated wood blocks is $13-14 \%$, while that of wood treated with phosphate flame retardant and $\mathrm{SiO}_{2}$ sol reaches $18-21 \%$. This illustrates that the effect of impregnation results is prominent. The mass of untreated wood after extraction is lost with average turnover rate (RL) of $0.48 \%$, which means there is almost nothing lost of wood itself. The mass loss of wood treated with phosphate flame retardants is obvious. It is reflected in that the RL reaches by $9-11 \%$ while WPG is $13-14 \%$, meaning a big loss of phosphate flame retardants. Besides, the LRV is only $20-32 \%$. That is to say, its performance of leach resistance is poor. The LRV of wood treated with the combination of phosphate flame retardants and $\mathrm{SiO}_{2}$ sol reaches $55-61 \%$, which is much bigger than that of wood treated with phosphate flame retardants. This means the wood treated with the combination of two materials have the better performance of leaching resistance. It can be explained that $\mathrm{SiO}_{2}$ sol has large specific surface area and strong absorbability, which helps to prevent the phosphate flame retardant from running off.

3.2. SEM-EDS. Figure 2 shows the SEM images of the surface of both transverse section and tangential section for untreated wood (S0) and treated wood samples (S1, S3, S4, and S6). It is clear that the vessel, wood fiber, and pit of poplar wood are interconnected. The porous structure of poplar wood is the main channels for phosphorus flame retardants and $\mathrm{SiO}_{2}$ sol into the poplar wood. It is obvious that no compound was detected in any part of the untreated wood blocks. When the samples were treated with phosphorus flame retardant (S1, S3), there are just white particles in the vessel, wood fiber, and wood ray. While the samples were treated with the mixture of phosphorus flame retardant and $\mathrm{SiO}_{2}$ sol $(\mathrm{S} 4, \mathrm{~S} 6)$, many agglomerates can be found in the vessel, wood fiber, wood ray, and pit. This is because the fluid can diffuse, resulting in the impregnation of agents into the wood.

To confirm the presence of flame retardants and $\mathrm{SiO}_{2}$ sol inside the cell of poplar wood, SEM-EDS mapping was carried out. Figure 3 shows the SEM-EDS map for the 


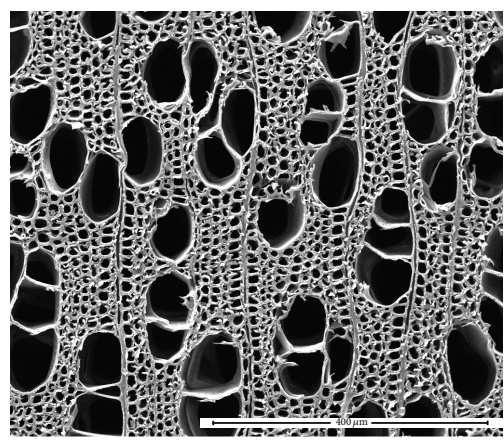

(a)

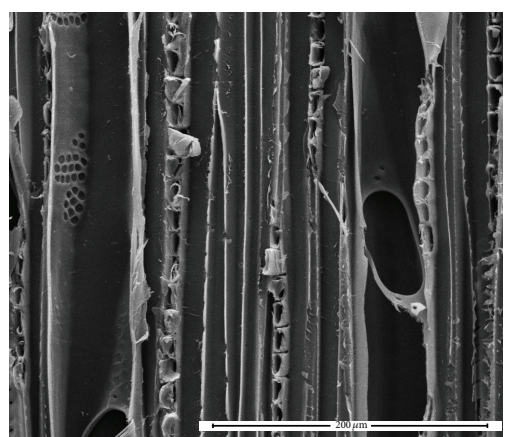

(d)

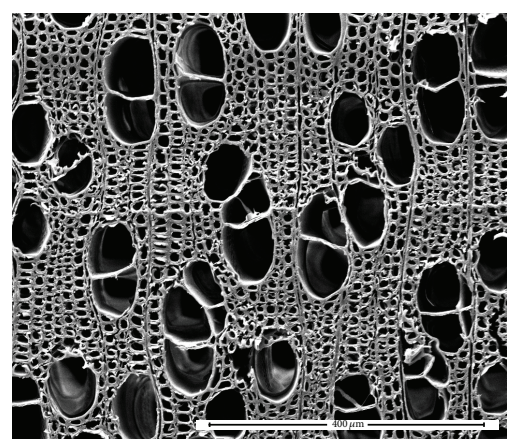

(b)

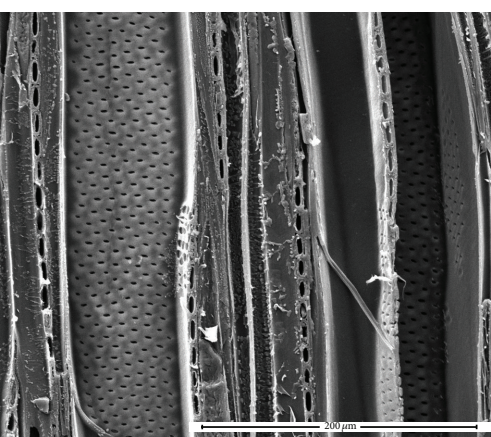

(e)

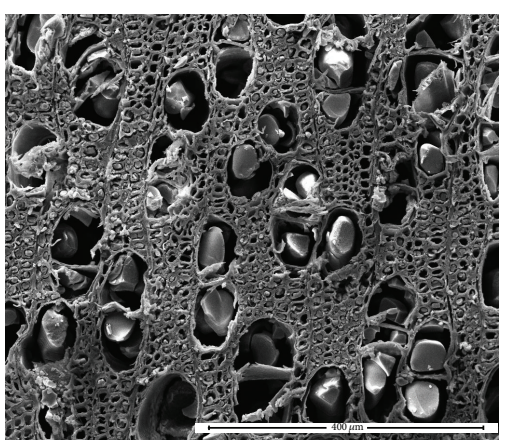

(c)

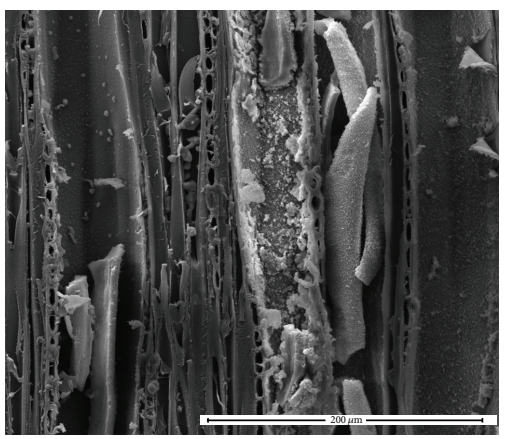

(f)

FIGURE 2: SEM images of the surface of transverse section of (a) S0, (b) S1, and (c) S4 and the tangential section of (d) S0, (e) S3, and (f) S6, respectively.
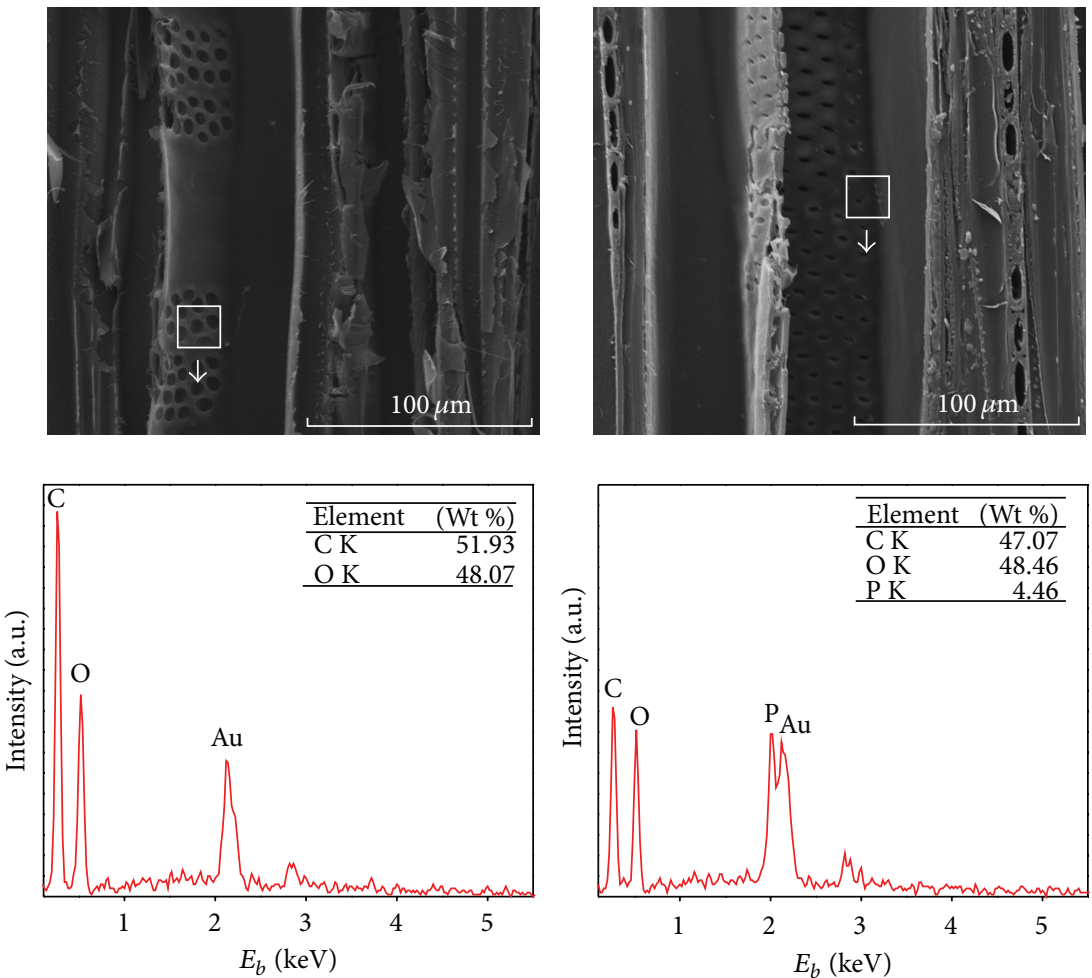

- S0

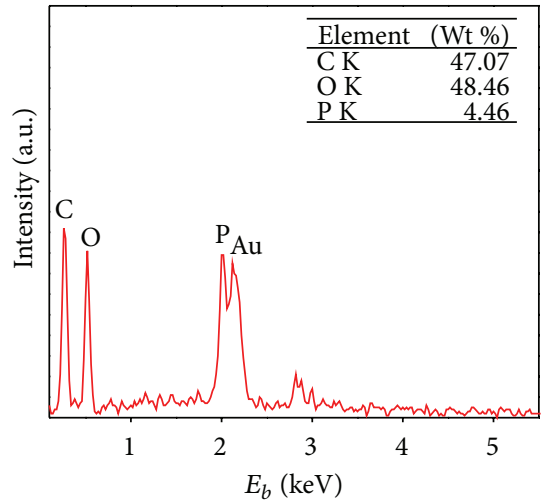

$-\mathrm{S} 2$
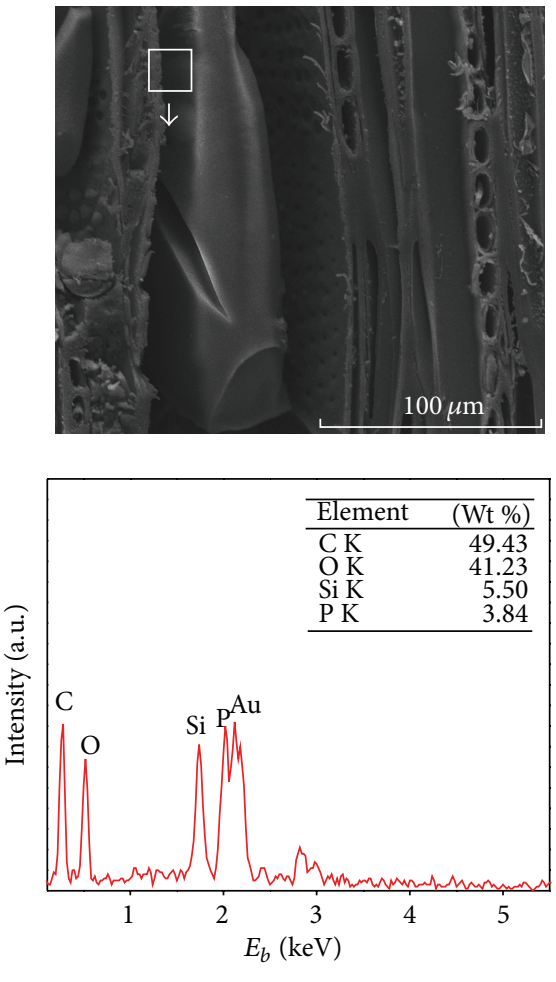

— S5

FIGURE 3: EDS spectral profiles of untreated (S0) and treated wood (S2, S5). 
TABLE 3: Values of combustion parameters for untreated and treated poplar wood.

\begin{tabular}{lcccc}
\hline Samples & THR $\left(\mathrm{MJ} / \mathrm{m}^{2}\right)$ & TSR $\left(\mathrm{m}^{2} / \mathrm{m}^{2}\right)$ & Mean COY $(\mathrm{kg} / \mathrm{kg})$ & $\mathrm{Mean}$ CO ${ }_{2} \mathrm{Y}(\mathrm{kg} / \mathrm{kg})$ \\
\hline S0 & 56.24 & 142.76 & 0.032 & 1.08 \\
S1 & 36.72 & 55.63 & 0.065 & 0.69 \\
S2 & 34.46 & 56.52 & 0.057 & 0.75 \\
S3 & 38.19 & 68.53 & 0.062 & 0.72 \\
S4 & 29.25 & 21.42 & 0.035 & 0.79 \\
S5 & 29.03 & 23.83 & 0.037 & 0.78 \\
S6 & 31.35 & 22.48 & 0.044 & 0.76 \\
\hline
\end{tabular}

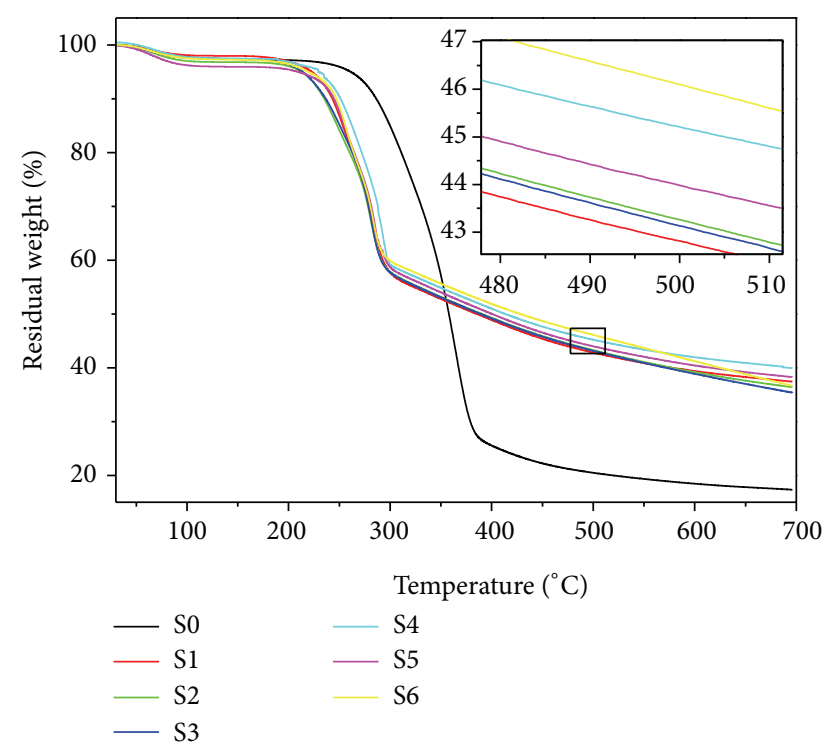

FIgURE 4: TGA data for untreated and treated wood.

untreated and treated blocks and indicates that there is no functional element except the basic elements of wood such as $\mathrm{C}$ and $\mathrm{O}$. When samples were treated with only phosphorus based flame retardant (S2), it was verified that the functional element $\mathrm{P}$ distribute inside porous structure of wood from the SEM-EDS analysis, although there was no obvious agglomerate block found in the vessel, wood fiber, and pit of wood. Additionally, the SEM-EDS images of the samples treated with both phosphorus flame retardants and $\mathrm{SiO}_{2}$ sol (S5) indicate that the $\mathrm{P}$ and $\mathrm{Si}$ elements exist concurrently in the wood cell. This means that phosphorus based flame retardants and $\mathrm{SiO}_{2}$ sol can reside in the poplar wood since poplar wood itself does not have $\mathrm{P}$ and $\mathrm{Si}$ elements. As the samples were obtained $3 \mathrm{~mm}$ from each radial, tangential, and transverse surface of the wood, it can be concluded that phosphorus flame retardants and $\mathrm{SiO}_{2}$ sol are easy to be brought by water into the poplar wood. Similarly, because the phosphorus flame retardants are water-soluble, this is why the phosphorus flame retardants are easy to be washed away by water.

3.3. Thermal Degradation. The TGA curves of untreated and treated poplar wood are shown in Figure 4. All the materials show three stages of decomposition. The first decomposition stage of all materials starts at $30^{\circ} \mathrm{C}$ and ends at $120^{\circ} \mathrm{C}$, which mainly is the evaporation of moisture resulting in about $1.5-3 \%$ of weight loss. In the range of $200^{\circ} \mathrm{C}-420^{\circ} \mathrm{C}$, the weight of untreated wood decreases significantly up to $76.01 \%$ due to the decomposition or dehydration of hemicellulose and the decomposition of cellulose [7]. Whereas the second decomposition stage of treated wood starts at $200^{\circ} \mathrm{C}$ and ends at $330^{\circ} \mathrm{C}$, the range of decomposition temperature is shorter than untreated wood, and the weight loss is only $42 \%-45 \%$, which is less than untreated wood. And the rate of weight loss of treated wood is faster than untreated wood during this temperature range. After that there is a gradual loss in both cases.

The thermal degradation of treated wood ends earlier than that of untreated wood, while the qualities of carbon residue of treated wood are higher than those of untreated group. All these indicate that flame retardants catalyze the decomposition of treated wood and advance the decomposition of wood. Simultaneously, flame retardants change the reaction mechanism and direction of decomposition of treated wood which can generate more carbon and water when the treated wood decompose $[7,8]$. What is more, the weight loss of the compound wood material treated with both phosphorus-containing flame retardants and $\mathrm{SiO}_{2}$ sol is even less than the wood treated with only phosphorus-containing flame retardants. The weight loss of S4, S5, and S6 is $60.28 \%$, $61.72 \%$, and $63.36 \%$, while the weight loss of S1, S2, and S3 is $62.59 \%, 63.65 \%$, and $64.63 \%$, respectively, indicating that $\mathrm{SiO}_{2}$ sol can further improve the flame retardation of wood, because the presence of $\mathrm{SiO}_{2}$ sol can enhance char formation of the matrix material and form a protective surface barrier to prevent the immediate damage of substrate materials [14].

\subsection{Flame-Retardation and Smoke-Suppression Character-} istics. The results of cone calorimeter tests for untreated and treated poplar wood are displayed in Figure 5 and Table 3. It is observed from Figure 5(a) and Table 3 that untreated wood burns very fast after ignition and a sharp heat release rate $(\mathrm{HRR})$ peak appearing with a pk-HRR as high as $309.40 \mathrm{~kW} / \mathrm{m}^{2}$, whose total heat release (THR) values are $56.24 \mathrm{MJ} / \mathrm{m}^{2}$. After treatment with phosphorus flame retardant, the HRR values all decrease by over $45 \%$. The THR values of treated wood are lowered by $30 \%$ to $40 \%$, which suggested that the addition of phosphorus flame retardant alone can improve the flame retardancy of wood. Besides, when the combination of phosphorus flame 


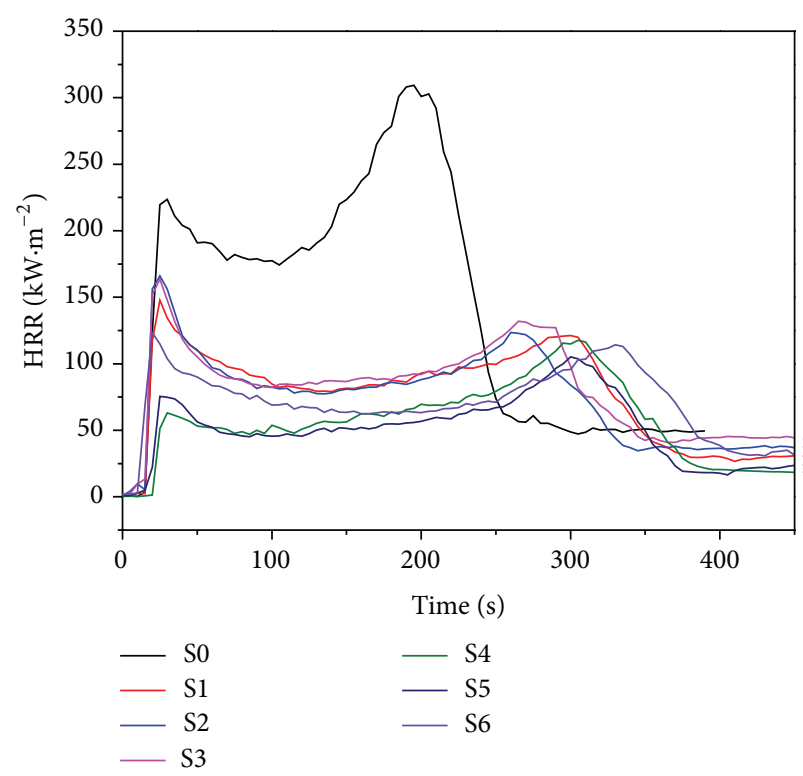

(a)

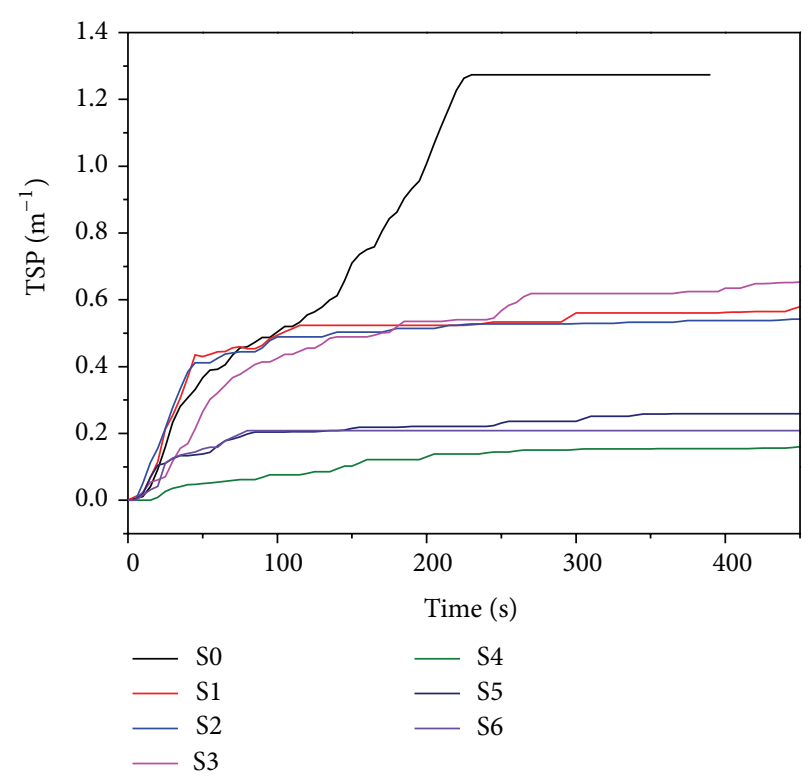

(b)

FIGURE 5: HRR (a) and TSP (b) as a function of time for untreated and treated poplar wood.

retardant and $\mathrm{SiO}_{2}$ aerogel is applied for wood, the HRR, pkHRR, and THR values show an obvious reduction compared with that of untreated wood, while present more reduction compared with that of wood treated with phosphorus flame retardant alone. For example, the poplar wood treated with APP and $\mathrm{SiO}_{2}$ aerogel whose THR values are $29.25 \mathrm{MJ} / \mathrm{m}^{2}$ reduces by $48 \%$ and $20 \%$, respectively, compared to that of untreated wood whose THR values are $56.24 \mathrm{MJ} / \mathrm{m}^{2}$ and that of APP treated wood whose THR values are $36.72 \mathrm{MJ} / \mathrm{m}^{2}$. These results demonstrated a synergistic effect of phosphorus flame retardant and $\mathrm{SiO}_{2}$ aerogel on improving the flame retardancy of wood. It can be illustrated that phosphorus flame retardants decompose at low temperature to form char residue layer on the surface of the sample, which acts as a barrier to prevent heat to underlying materials and flammable gases into flame zone. On the other hand, $\mathrm{SiO}_{2}$ aerogel significantly enhances the thermal stability of carbon, thus forming a defending charring layer of $\mathrm{Si}-\mathrm{O}-\mathrm{C}$ and $\mathrm{Si}-\mathrm{C}$ bonds, which protect the poplar wood from burning.

Figure 5(b) shows the total smoke production (TSP) curves of wood at a flux of $50 \mathrm{~kW} / \mathrm{m}^{2}$ in the cone calorimeter test. The total smoke release (TSR), mean CO yield (COY), and $\mathrm{CO}_{2}$ yield $\left(\mathrm{CO}_{2} \mathrm{Y}\right)$ parameters can be seen in Table 3 . As is portrayed in Figure 5(b), the distinction between pure wood and the flame retarded samples is apparent. Furthermore, the TSP values of wood significantly decrease with the addition of $\mathrm{SiO}_{2}$ aerogel. According to Table 3, the TSR of wood that was treated with phosphorus flame retardants alone and the combination of phosphorus flame retardants and $\mathrm{SiO}_{2}$ aerogel was reduced by $51-62 \%$ and $83-$ $85 \%$, respectively, compared to untreated wood. However, the mean COY of wood treated with phosphorus flame retardants is much higher than that of untreated wood. While $\mathrm{SiO}_{2}$ aerogel is incorporated into the system, the mean COY can reduce almost the same to that of untreated wood. Besides, the $\mathrm{CO}_{2} \mathrm{Y}$ of treated wood is all lower than that of untreated wood, while the $\mathrm{SiO}_{2}$ aerogel can inhibit the release of smoke and toxic gases, which are the leading cause of fire casualties. The phosphorus flame retardants act by the condensed phase mechanism, during which dehydration of the substrates leads to form more char, and protective coating of polyphosphoric acid, phosphorus oxynitride structures or polyphosphoramidic structures on the surface of burning material is formed, resulting in the fact that less smoke and gas were generated from wood [15]. The reason for good smoke suppression of nano- $\mathrm{SiO}_{2}$ aerogel is attributed to the $\mathrm{SiO}_{2}$ with highly adsorptive capacity and catalytic conversion effect on the release of smoke and gas.

3.5. FT-IR Spectroscopy. The FTIR spectra of wood treated with phosphorus and silicon-phosphorus flame retardant are shown in Figure 6. It can be seen that most of the characteristic peaks of treated wood are similar to those of untreated one. The FTIR spectrum of wood treated with phosphorus flame retardant (S1, S2, S3) shows an absorption band at $1250-1253 \mathrm{~cm}^{-1}$, attributed to the stretching vibration of $\mathrm{P}=\mathrm{O}$. The FTIR spectrum of wood treated with siliconphosphorus flame retardant $(\mathrm{S} 4, \mathrm{~S} 5, \mathrm{~S} 6)$ indicated that the composite not only has the peaks of phosphorus-oxygen bond which can prove that the phosphorus flame retardant exists in the poplar wood, but also shows new intensities of peak which is proof that silica aerogel is present in the wood. The FT-IR peaks of $1080-1110 \mathrm{~cm}^{-1}$ and $450-460 \mathrm{~cm}^{-1}$ corresponded to the asymmetric stretching of linear Si-O$\mathrm{Si}$ and bending vibration $\mathrm{Si}-\mathrm{O}-\mathrm{Si}[16,17]$. The absorption band located between 1020 and $1040 \mathrm{~cm}^{-1}$ ascribes to Si$\mathrm{OH}$ groups [18]. What is more, the peak of $3000-3500 \mathrm{~cm}^{-1}$ which correspond to the stretching vibration of $\mathrm{OH}$ of treated 


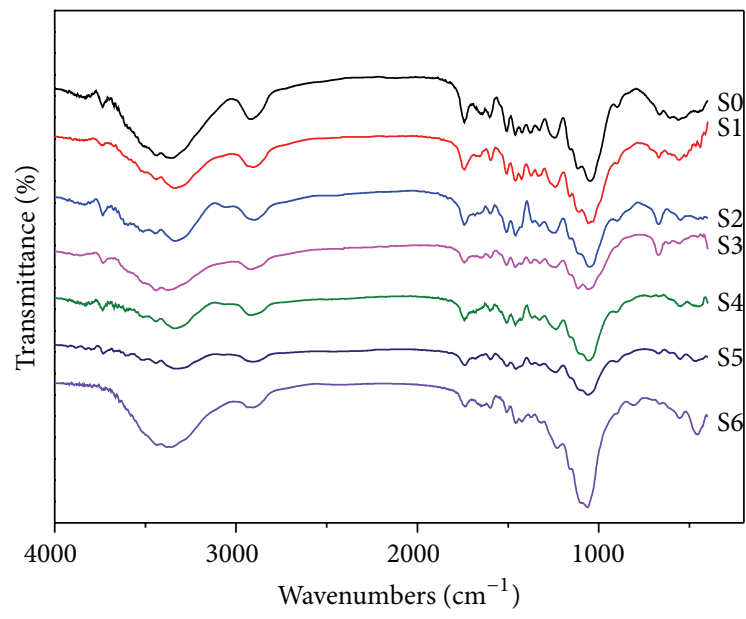

FIGURE 6: FTIR spectra of untreated and treated wood.

wood is different than that of untreated group; that is to say, the phosphorus flame retardants or $\mathrm{SiO}_{2}$ aerogel may bond with wood cellulose by hydrogen bonds.

\section{Conclusion}

The nano- $\mathrm{SiO}_{2}$ sol, obtained by sol-gel method, combined with three different phosphate flame retardants to treat wood in order to improve the flame retardancy and leaching resistance of wood. The SEM and SEM-EDS results showed that phosphorus flame retardants and $\mathrm{SiO}_{2}$ sol resided in the poplar wood and widely distributed in the vessels, pits, wood timber, and the spaces between wood cells of poplar substrate. TGA indicated that phosphorus flame retardants could significantly improve the thermal stability of wood, while the $\mathrm{SiO}_{2}$ sol could further enhance the thermal stability of the system. It was found that phosphorus flame retardant and nano- $\mathrm{SiO}_{2}$ aerogel have a synergistic effect on improving the flame retardation of wood by CONE test. Besides, the combination of phosphorus flame retardants and nano- $\mathrm{SiO}_{2}$ aerogel exerts a significant influence on inhibiting the release of smoke and toxic gases in the combustion processes, while the phosphorus flame retardants alone would lead to more smoke and toxic gases than untreated wood. In addition, the average LRV of composite could reach $55-61 \%$, while that of untreated wood was $20-32 \%$ by a leaching resistance test, which means the phosphorus flame retardants were able to be fixed in the wood by nano- $\mathrm{SiO}_{2}$ aerogel.

\section{Conflict of Interests}

The authors declare that there is no conflict of interests regarding the publication of this paper.

\section{Acknowledgments}

This work was financially supported by the National Science and Technology Pillar Program during the Twelfth Five-year Plan Period (2012BAD24B03), National Natural and Science
Foundation of China (31070496), the financial support from Significant Program of Forestry Industry Special Funds for Public Welfare of China (201204704), and Hunan Provincial Innovation Foundation For Postgraduate (CX2013B346).

\section{References}

[1] T. R. Hull, A. Witkowski, and L. Hollingbery, "Fire retardant action of mineral fillers," Polymer Degradation and Stability, vol. 96, no. 8, pp. 1462-1469, 2011.

[2] Y. Fang, Q. Wang, C. Guo, Y. Song, and P. A. Cooper, "Effect of zinc borate and wood flour on thermal degradation and fire retardancy of Polyvinyl chloride (PVC) composites," Journal of Analytical and Applied Pyrolysis, vol. 100, pp. 230-236, 2013.

[3] Y. Yen, H. Wang, and W. J. Guo, "Synergistic effect of aluminum hydroxide and nanoclay on flame retardancy and mechanical properties of EPDM composites," Journal of Applied Polymer Science, vol. 130, no. 3, pp. 2042-2048, 2013.

[4] Y. Q. Wu, C. H. Yao, Y. C. Hu, S. L. Yang, Y. Qing, and Q. $\mathrm{L}$. Wu, "Flame retardancy and thermal degradation behavior of red gum wood treated with hydrate magnesium chloride," Journal of Industrial and Engineering Chemistry, vol. 20, no. 5, pp. 3536-3542, 2014.

[5] J. X. Jiang, J. Z. Li, J. Hu, and D. Fan, "Effect of nitrogen phosphorus flame retardants on thermal degradation of wood," Construction and Building Materials, vol. 24, no. 12, pp. 26332637, 2010.

[6] F. Shukor, A. Hassan, I. M. Saiful et al., "Effect of ammonium polyphosphate on flame retardancy, thermal stability and mechanical properties of alkali treated kenaf fiber filled PLA biocomposites," Materials \& Design, vol. 54, pp. 425-429, 2014.

[7] M. Gao, C. Y. Sun, and C. X. Wang, "Thermal degradation of wood treated with flame retardants," Journal of Thermal Analysis and Calorimetry, vol. 85, no. 3, pp. 765-769, 2006.

[8] Z. X. Zhang, J. Zhang, B.-X. Lu, Z. X. Xin, C. K. Kang, and J. K. Kim, "Effect of flame retardants on mechanical properties, flammability and foamability of PP/wood-fiber composites," Composites B: Engineering, vol. 43, no. 2, pp. 150-158, 2012.

[9] A. Gentilhomme, M. Cochez, M. Ferriol, N. Oget, and J. L. Mieloszynski, "Thermal degradation of methyl methacrylate polymers functionalized by phosphorus-containing molecules. III: cone calorimeter experiments and investigation of residues," Polymer Degradation and Stability, vol. 88, no. 1, pp. 92-97, 2005.

[10] Y. C. Chiu, F. Y. Liu, C. M. Ma et al., "Syntheses and characterization of novel P/Si polysilsesquioxanes/epoxy nanocomposites," Thermochimica Acta, vol. 473, no. 1-2, pp. 7-13, 2008.

[11] J. Alongi, M. Ciobanu, and G. Malucelli, "Novel flame retardant finishing systems for cotton fabrics based on phosphoruscontaining compounds and silica derived from sol-gel processes," Carbohydrate Polymers, vol. 85, no. 3, pp. 599-608, 2011.

[12] S. Palanti, G. Predieri, F. Vignali, E. Feci, A. Casoli, and E. Conti, "Copper complexes grafted to functionalized silica gel as wood preservatives against the brown rot fungus Coniophora puteana," Wood Science and Technology, vol. 45, no. 4, pp. 707$718,2011$.

[13] H. Miyafuji, S. Saka, and A. Yamamoto, " $\mathrm{SiO}_{2}-\mathrm{P}_{2} \mathrm{O}_{5}-\mathrm{B}_{2} \mathrm{O}_{3}$ wood-inorganic composites prepared by metal alkoxide oligomers and their fire-resisting properties," Holzforschung, vol. 52, no. 4, pp. 410-416, 1998.

[14] F. Yang and G. L. Nelson, "Polymer/silica nanocomposites prepared via extrusion," Polymers for Advanced Technologies, vol. 17, no. 4, pp. 320-326, 2006. 
[15] H. Getto and S. Ishihara, "Functionally graded wood in fire endurance with basic nitrogen compounds and phosphoric acid," Fire and Materials, vol. 22, no. 2, pp. 77-83, 1998.

[16] A. Kioul and L. Mascia, "Compatibility of polyimide-silicate ceramers induced by alkoxysilane silane coupling agents," Journal of Non-Crystalline Solids, vol. 175, no. 2-3, pp. 169-186, 1994.

[17] T.-C. Mo, H.-W. Wang, S.-Y. Chen, R.-X. Dong, C.-H. Kuo, and Y.-C. Yeh, "Synthesis and characterization of polyimide-silica nanocomposites using novel fluorine-modified silica nanoparticles," Journal of Applied Polymer Science, vol. 104, no. 2, pp. 882-890, 2007.

[18] C. J. Cornelius and E. Marand, "Hybrid inorganic-organic materials based on a 6FDA-6FpDA-DABA polyimide and silica: physical characterization studies," Polymer, vol. 43, no. 8, pp. 2385-2400, 2002. 

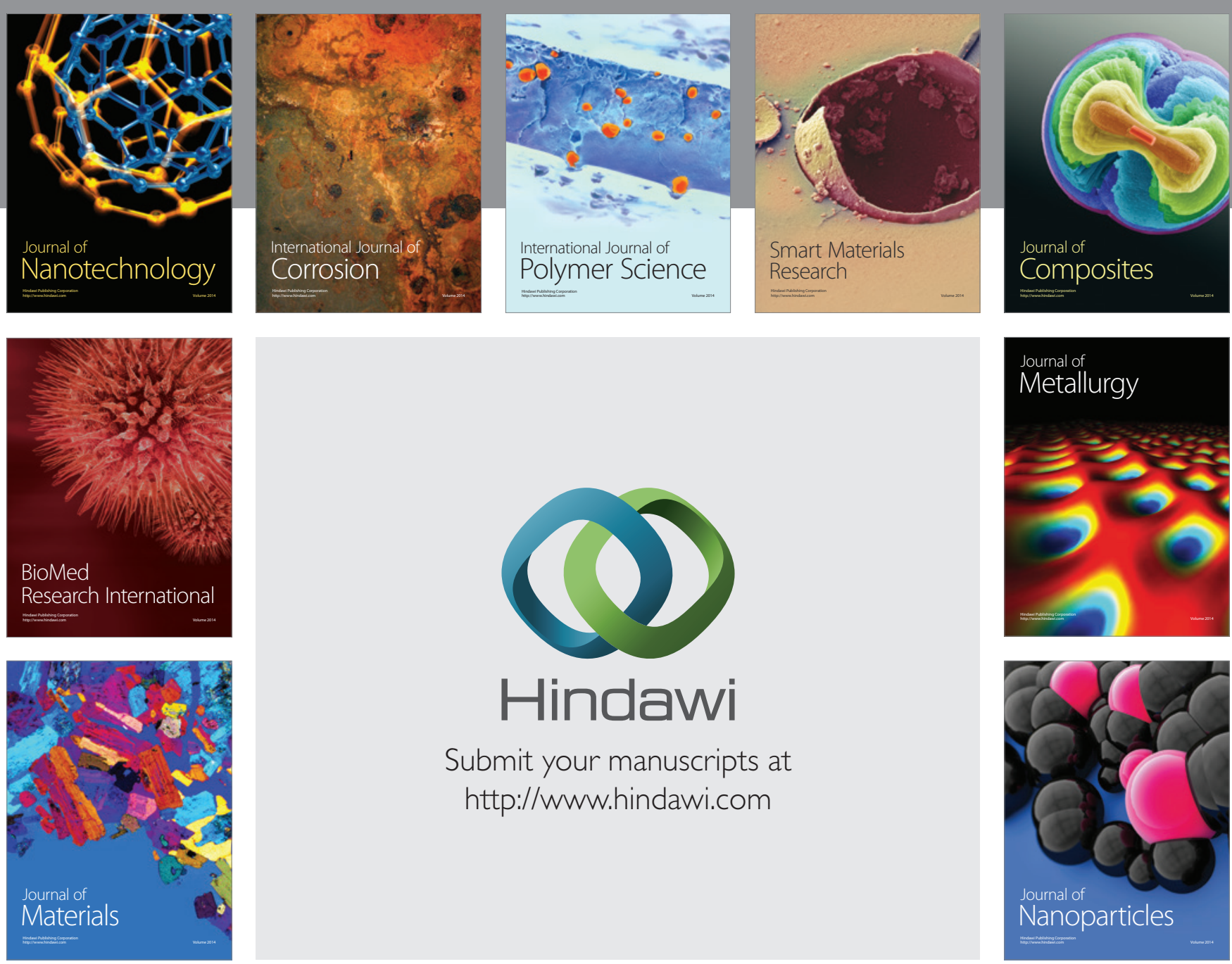

Submit your manuscripts at http://www.hindawi.com
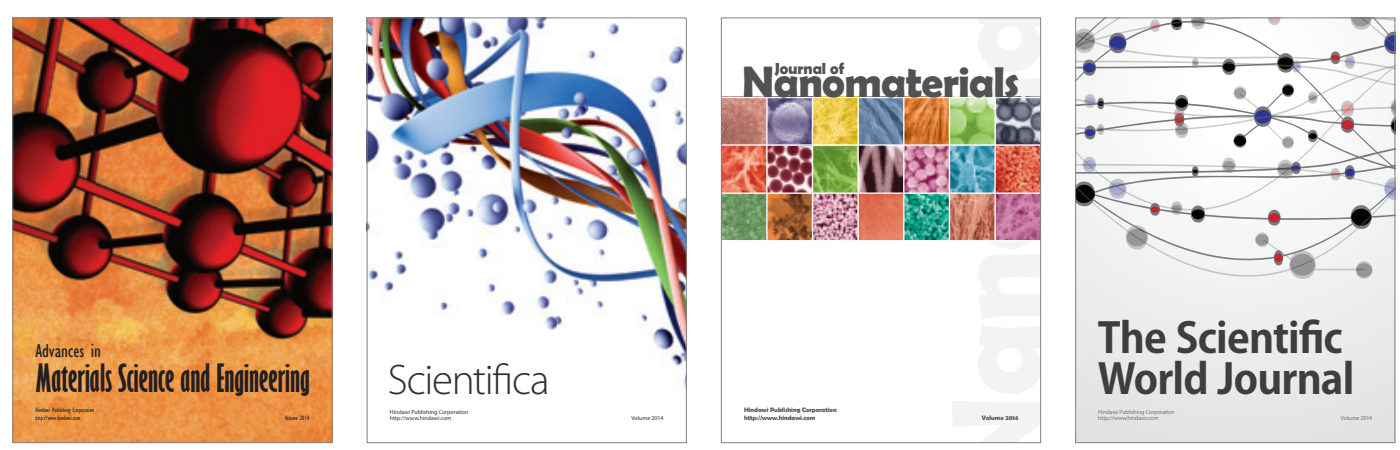

\section{The Scientific World Journal}
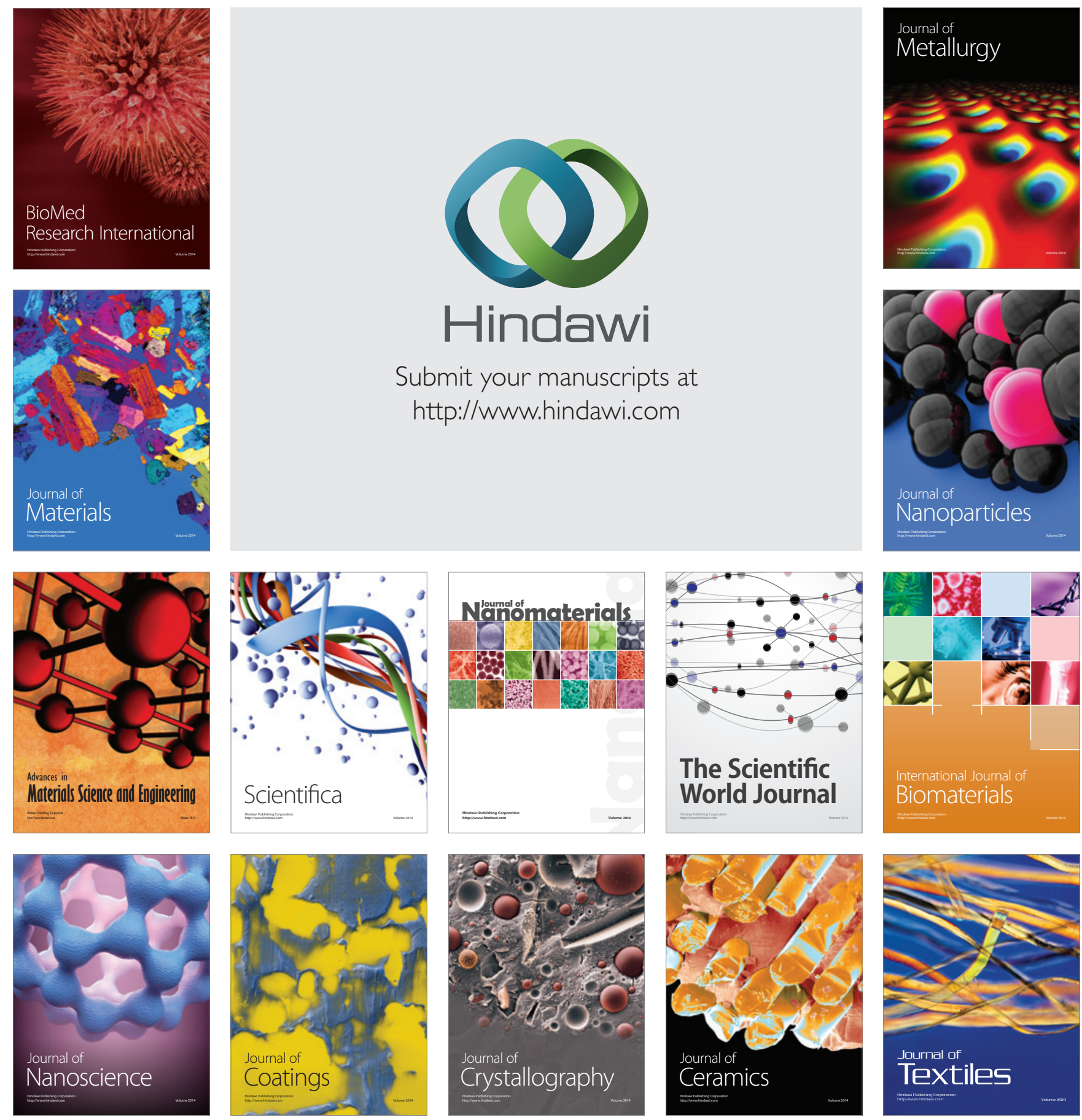